\title{
RESEARCH
}

\section{Current State and Opportunities for Enhancing Peer Evaluation Practices Across the Pharmacy Academy}

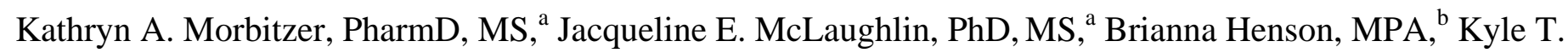
Fassett, PhD, MSEd, MA, ${ }^{a}$ Margarita V. DiVall, PharmD, MEd ${ }^{\mathrm{c}}$

${ }^{a}$ University of North Carolina at Chapel Hill, UNC Eshelman School of Pharmacy, Chapel Hill, North Carolina

${ }^{\mathrm{b}}$ University of Kentucky, College of Pharmacy, Lexington, Kentucky

${ }^{c}$ Northeastern University, School of Pharmacy, Boston, Massachusetts

Corresponding Author: Kathryn Morbitzer, University of North Carolina, UNC Eshelman School of Pharmacy, 301 Pharmacy Lane, Campus Box 7574, Chapel Hill, NC 27599. Tel: 919-966-9124. Email: kmorbitzer@unc.edu

Submitted September 9, 2021; accepted December 23, 2021; ePublished January 2022

Objective. To examine and summarize policies and procedures for peer evaluation of teaching/instructional coaching (PET/IC) programs within departments, schools, and colleges of pharmacy and to identify opportunities for improving these based on best practices.

Methods. A survey was sent to all ACPE-accredited pharmacy programs to collect information regarding procedures to support and evaluate PET/IC programs across institutions. Descriptive statistics were used to summarize the general features of PET/IC programs and inferential statistics were used to make group comparisons based on institutional control (public, private) and institution age (0-10 year, older than 10 years).

Results. Surveys for 91 institutions were completed (response rate $=64.5 \%$ ). Most institutions $(78.4 \%)$ reported having a PET/IC program. Most institutions with PET/IC programs reported using a combination of formative and summative evaluations (57.4\%). Faculty development (35.8\%) and improving teaching (35.8\%) were the top purposes for PET/IC programs. Almost half of the PET/IC programs (46.3\%) were mandatory for all faculty at the institutions. Most institutions $(66.7 \%)$ had one standardized instrument used in their PET/IC program. Few institutions (11.9\%) reported evaluating or being in the process of evaluating the effectiveness or success of their PET/IC program. Private institutions were more likely to incentivize observers than public institutions $(17.1 \%$ vs. $0 \%)$.

Conclusion. PET/IC programs are needed to assess and provide feedback to instructors about their teaching practices. While most institutions report having a PET/IC program, wide variability exists in how the programs are implemented. Opportunities exist for institutions to evaluate the effectiveness of their program and identify best practices.

Keywords: peer evaluation, peer assessment, peer observation, instructional coaching

\section{INTRODUCTION}

Effective teaching is critical to prepare the next generation of pharmacists. Therefore, the need to evaluate teaching effectiveness exists for all colleges and schools of pharmacy. As the pharmacy profession continues to expand the role of pharmacists and emphasize a team-based, multidisciplinary model of care, there is a need to improve the quality of pharmacy education. To do this requires committed, knowledgeable, and competent pharmacy educators. ${ }^{1-3}$ Studies indicate that, although health professions educators are experts in the content they teach, they rarely receive training on effective teaching practice. ${ }^{1-2}$

Commonly, student course evaluations are used to assess teaching effectiveness. However, there is increasing recognition that these should not be the sole method of informing teaching effectiveness. ${ }^{4-6}$ Student course evaluations may be influenced by an instructor's charisma or communication style rather than the instructor's ability to improve knowledge, understanding, and application of material through evidence-based teaching strategies. ${ }^{7-9}$ Student course evaluations may also be affected by factors that are beyond the instructor's control, such as logistical and scheduling issues and learner motivation, or even racial and gender bias. ${ }^{7,10}$

Peer evaluation of teaching offers another method to assess and provide feedback to instructors about their teaching practices for improving the quality of teaching and/or informing personnel decisions. Two types of peer evaluation generally exist - formative evaluation and summative evaluation. ${ }^{9}$ Formative evaluation is designed to provide feedback that informs teaching with an intention for personal use and can also be known as "instructional coaching", "peer feedback", or "peer observation". This contrasts with summative evaluation, which is designed to provide 
information that informs decision-making by the institution (eg, promotion, reappointment, merit awards) and is typically intended for use by others. This summative type of peer evaluation is often also known as "peer review".

Within the pharmacy academy, several institutions have published on the implementation and impact of their peer evaluation of teaching program. ${ }^{11-18}$ Based on these publications and others in higher education, it is possible to develop suggested peer evaluation of teaching process considerations (Table 1). ${ }^{11-19}$ However, as neither the American Council of Pharmaceutical Education (ACPE) nor the American Association of Colleges of Pharmacy (AACP) provide guidance on recommended components and processes for peer evaluation of teaching, variability in the presence, purpose, and operationalizing of peer evaluation programs exists. The purpose of this research was to examine and summarize policies and procedures for peer evaluation of teaching within departments, schools, and colleges of pharmacy and to identify opportunities for improvement of such programs based on best practices reported in the literature.

\section{METHODS}

Researchers developed a web-based survey (Qualtrics, Inc, Provo, UT), using their expertise and results of a literature search focused on best practices in peer evaluation of teaching and instructional coaching. For the purposes of the study, terms "peer evaluation of teaching (PET)" and "instructional coaching (IC)" were used interchangeably. Peer evaluation of teaching/instructional coaching (PET/IC) was defined as: the review of teaching performance by colleagues, usually in the same or a similar discipline, with the purpose of assessing and improving the quality of teaching. ${ }^{20}$

As part of the survey development, researchers identified objectives for the study and created items related to each objective. These objectives included: 1) identify the breadth and depth of ongoing peer evaluation of teaching/ instructional coaching across institutions, 2) determine common procedures to support such evaluation/ coaching, 3) determine whether institutions have evaluated the success and impact of such programs on teaching and learning. The research team members generated items, iterated to improve item clarity, and met to finalize the survey. After the research team agreed upon the final survey instrument, five faculty at different ranks at two institutions pretested the questionnaire and provided feedback. The final survey instrument used skip logic and consisted of a maximum of 41 questions plus 2 demographic questions. Definitions were given for terms, including peer evaluation of teaching/ instructional coaching and formative and summative evaluations, in order to increase the consistency in responses.

Northeastern University Institutional Review Board deemed the questionnaire exempt. In October 2020, the survey invitation was emailed to 141 pharmacy program assessment leads. They were asked to contact investigators if the survey should be sent to an alternative individual and to complete only one survey per program, consulting with colleagues as needed. A PDF of the questionnaire was provided to assist with this request. Due to COVID-19 disruptions the survey remained open through March 2021, with numerous Qualtrics-based reminders, emails, and phone call followups to attain satisfactory response rate. Responses were linked to pharmacy programs but analyzed collectively. All survey items are described using frequency and percent. Differences by institutional control (ie, publicly-controlled vs privately-controlled) and age (ie, established $<10$ years age, 10+ years) were explored using Chi-Square Tests with Fisher's Exact Test where appropriate $(\mathrm{ie}, \mathrm{n}<5)$. Statistical significance was established at $p<.05$.

\section{RESULTS}

Surveys for 91 institutions were completed (response rate $=64.5 \%)$. Most were publicly-funded $(\mathrm{n}=49,54 \%)$ and the others were privately-funded $(n=42,46 \%)$. The year the schools were established ranged from 1823 to 2017. Most institutions $(n=69,78.4 \%)$ had a PET/IC program, with fewer developing $(n=4,4.5 \%)$ or not $(n=15,17 \%)$ having a program at all. Those with PET/IC programs were proportionally representative of the institutional control for all 141 US pharmacy schools (publicly-funded, $\mathrm{n}=32,46 \%$ vs $\mathrm{N}=68,48 \%$ and privately-funded $\mathrm{n}=37,54 \%$ vs $\mathrm{N}=73,52 \% ; p=0.80$ ) and representative of the age of all schools (up to 10 years, $\mathrm{n}=7,10 \%$ vs $\mathrm{N}=18,13 \%$ and $10+$ years $\mathrm{n}=62,90 \%$ vs $\mathrm{N}=123,87 \% ; p=0.58$ ).

As seen in Table 2, most institutions with PET/IC reported using a combination of formative and summative evaluations $(n=39,57.4 \%)$. Few used only formative evaluations $(n=19,27.9 \%)$ or summative evaluations $(n=10$, $15.0 \%)$. Faculty development $(n=24,35.8 \%)$ and improving teaching $(n=24,35.8 \%)$ were the top purposes for PET/IC programs. Less common purposes consisted of meeting requirements for tenure \& promotion $(n=14,20.9 \%)$ and improving student learning $(n=5,7.5 \%)$. Fulfilling requirements for accreditation and providing data for merit awards were not considered primary purposes for PET/IC programs. Most did not have additional centers or services at the university to support PET/IC ( $n=52,77.6 \%)$. Most also did not make any changes to their process/policy during COVID$19(n=41,60.3 \%)$.

Almost half of the PET/IC programs were mandatory for all faculty at the institution $(n=31,46.3 \%)$. Of the 31 institutions that required faculty participation in PET/IC programs, over one-third $(n=12,38.7 \%)$ stated there were 
consequences for not participating. Nearly one-quarter $(n=16,24.2 \%)$ of the institutions reported having a unified method of instruction. Most faculty picked when their class was going to be observed $(n=53,79.1 \%)$. When asked to indicate core aspects of the PET/IC review process, institutions most commonly offered classroom observations $(n=67,97.1 \%$ of $69)$ and post class observation meetings $(n=39,56.5 \%)$. Thirty institutions $(43.5 \%)$ reported including a pre-class meeting in their process, $30(43.5 \%)$ included self-reflection by the instructor, and only $18(26.1 \%)$ included post-assessment meeting. Instructional materials (eg, handouts, presentation slides, assignments, homework) ( $n=60,87 \%)$ and student reactions/perceptions during peer evaluation $(n=29,42 \%)$ were most commonly included in the PET/IC review process. A teaching portfolio $(n=9,13 \%)$ and results of assessments (ie, student performance) $(n=13,18.8 \%)$ were included the least.

As it relates to PET/IC instruments, most had one standardized instrument $(n=44,66.7 \%)$ while others had multiple standardized $(n=10,15.2 \%)$ or no standardized $(n=12,18.2 \%)$ instruments. Of those institutions who had at least one instrument, most developed their own $(n=29,53.7 \%)$. Nine institutions $(16.7 \%)$ reported validating their instrument. Nine out of ten institutions reported not incentivizing faculty to conduct peer observations $(n=59,90.8 \%)$.

When asked to select all training options offered, participants most commonly reported having no formal training process $(n=47,68.1 \%)$ for peer observers. When asked to select all methods of sharing observation results, participants indicated that they most commonly shared the completed instrument $(n=51,73.9 \%)$, engaged in verbal discussion about results $(n=46,66.7 \%)$, and provided a letter summarizing the results $(n=25,36.2 \%)$.

Department Chairs $(n=29,43.3 \%)$ most often had the primary responsibility for overseeing the processes associated with PET/IC programs (eg, communication of policies). As indicated by write-in responses, other faculty committees, faculty administrators, and staff members frequently oversaw evaluation processes as well $(n=23,34.3 \%)$. Chi-square results indicated privately controlled institutions more frequently incentivized peer observers $(n=6)$ than publicly controlled institutions $(\mathrm{n}=0, \mathrm{p}=.03)$. Roughly one in ten institutions reported evaluating $(n=8,11.9 \%)$ or being in the process of evaluating the effectiveness or success of their PET/IC program $(n=8,11.9 \%)$. In other words, most institutions $(n=51,76.1 \%)$ have not evaluated the effectiveness of their PET/IC program.

\section{DISCUSSION}

To prepare faculty to meet the dynamic needs of the student population requires schools or colleges of pharmacy to consistently evaluate their teaching effectiveness and quality to provide a premier student experience. Over the decades, PET has become a prevalent way for faculty to measure and improve their teaching quality to better meet the needs of students. The United States, Australia, and United Kingdom are countries that have the most widespread use of PET. ${ }^{20}$ PET has become an additional component of the comprehensive assessment of teaching in addition to other measures of teaching effectiveness. ${ }^{21}$ As a result, teaching has moved from a singular to a community enterprise for improvement. ${ }^{22}$ ACPE Standard 10 requires for the curriculum to be delivered via teaching methods that incorporate strategies to address the learning needs of students and facilitate achievement of course expectations and outcomes, but does not mandate a quality assurance process for faculty to provide feedback on the teaching and learning process. ${ }^{3}$

Our study found that most institutions have a PET/IC program. However, we also found that the variability in the PET/IC programs across the academy is broad. As this may be appropriate due to different schools having different pedagogical models and incentive structures for faculty, the lack of a universal standard for how to analyze and foster peer review is also potentially problematic as it may result in a lack of awareness in whether instructors are utilizing evidencebased teaching practices. Thus, opportunities exist for the academy to improve PET.

PET has historically taken the forms of a formative or summative approach in higher education. In our study, most institutions with PET/IC programs reported using a combination of formative and summative evaluations. Both assessment approaches to PET have been shown to help faculty reflect on their teaching, increase their confidence, feel less isolated, enhance student learning experiences, improve their teaching, create community and collegiality, and help faculty critically reflect upon social constructs that play a role in teaching. ${ }^{23-30}$ It's imperative that PET programs should be viewed as a holistic process where pedagogy is able to be discussed, critiqued, transformed, and preserved.

There is limited literature in pharmacy education establishing best practices for PET, however, other disciplines have published guidelines. Successful PET programs need an explicit framework to ensure success. Evaluations should incorporate appropriate evidence and processes to ensure fairness, consistency, and the reliability of data. ${ }^{31}$ Evaluation methods should be reflective of the college's mission, values, and practices. Rubrics and other assessment methods are recommended to be identified and validated so that the measure is accurately able to assess teaching impact and allow for faculty to track their progress for continual improvement of instruction. This is an area, in particular, in which the pharmacy academy can improve as only $16.7 \%$ of institutions surveyed reported using a validated instrument in their PET/IC process. Reynolds et al. suggest rubrics should be developed to assess four distinct criteria: disciplinary expertise, 
design and development skills, instructional practices and performance, and teaching environment. ${ }^{32}$ Each criteria is broken down into subcategories with descriptive statements to further explain each criteria in detail.

Many higher education institutions provide a central teaching and learning center to support faculty instruction regardless of discipline. However, it is encouraged for colleges of pharmacy to develop their own center that reconnects teaching to the discipline. By doing this, effort is made to value and reconnect teaching as a vital part of the student experience by engaging faculty in the scholarship of their profession. ${ }^{23,33}$

After reviewing the literature, the authors have developed some suggested best practices for the creation and maintenance of a PET program in conjunction with Trujillo et al. recommended steps as outlined in Table $1 .{ }^{34}$ Reflection and feedback should be incorporated and seen as a valuable part of the review process, preferably with a meeting occurring to foster discussion rather than only written feedback. Feedback should appear as non-threatening and there should be sufficient time to discuss findings. ${ }^{35}$ Creating this safe space will encourage faculty to experiment in new and innovative ideas without feeling threatened, anxious, embarrassed, or causing negative internal dialogue. ${ }^{35}$ Some examples of providing feedback as non-threatening and creating a safe space include programs trying to make PET as transparent as possible by utilizing video to record the reviewee and the pre- and post-discussions with the evaluators and faculty being reviewed. ${ }^{36}$ Other programs allow for the faculty being evaluated to observe and assess their own teaching prior to the post-review meeting to allow them the opportunity to identify challenges and solutions, which creates the opportunity of having a two-way dialogue and the feedback session being more conversational. ${ }^{29}$ There are also examples of programs providing feedback only to the faculty member being evaluated and then allowing the faculty member to determine if they want to share the feedback with any others (eg, their department chair). ${ }^{19}$ In our study, it was apparent that in many institutions there are opportunities to improve PET by enhancing the feedback provided by incorporating additional elements as part of the process, such as pre-observation meeting and consistent timeline and expectations for post-observation meetings and feedback. Additionally, programs should consider incorporating the review of assessments as part of the process to ensure the quality of both teaching and learning.

There are few formal training programs that prepare faculty to conduct peer reviews. Most faculty receive informal mentoring from committee members or staff. ${ }^{36}$ In some instances, more experienced faculty are selected as observers. ${ }^{37,38}$ Regardless of previous teaching experience or type of faculty appointment, peer reviewers should receive guidance and training to better understand pedagogical approaches. As each institution is unique, it is recommended for each college of pharmacy and department to encourage a formal training process based on best practices and establish a culture where performance measures are created through faculty consensus, ongoing mentorship, and have evaluations linked to meaningful outcomes. ${ }^{36}$ In our study only $31.9 \%$ of the institutions reported formal training for peer observers. Peer reviewers should receive appropriate training and orientation on how to rate peers against a professional standard, collect evidence, and provide feedback. Training should be developed by senior faculty in conjunction with educational experts. All of these are ways to increase trust, mutual respect, consider sociocultural differences, and minimize bias.

A lack of thoughtful and comprehensive approach towards evaluation standards can often result in bias from the evaluators. This can present disadvantages to historically underrepresented groups (HUGs) where structural and institutional barriers exist. To combat this, the reliability of PET can be improved through the use of standardized evaluation tools, training of evaluators, reflections, discussions, and intentionally recognizing and celebrating sociocultural norms, values, and conventions. Limited literature recognizes the impact of sociocultural contexts in the peer review process. Sociocultural perspectives should be recognized and discussed during the process as they contribute to the department and college's norms, rules, attitudes, and ways that faculty communicate, support, and engage with each other and students. A climate built on trust, support, and common goals facilitate open communication to allow for peer review to be successful. ${ }^{37}$ As institutions have increasingly been encouraged to acknowledge and separate themselves from parts of their discriminatory history, the review process should articulate, embrace, value, and respect faculty who have different cultural intersections within the department or institution. Incorporating peer reviewers who belong to HUGs are one way to mitigate patterns of discrimination that may appear in the review process.

Our study revealed that very few institutions have evaluated the effectiveness and impact of the PET/IC programs, which remains one of the largest opportunities to identify how these programs can have a meaningful impact on teaching and learning across the academy. One example of an institution evaluating their PET/IC program involved administering a pre-implementation survey assessing faculty needs and attitudes related to peer evaluation, then two years after implementation, the survey was repeated and additional questions were asked regarding adherence to peer observation policies and procedures, feedback received, and impact on teaching. ${ }^{13}$ There remains little known on the direct connection between PET/IC programs and student attainment of knowledge and skills. It is also suggested PET should be used in combination with and to supplement other teaching effectiveness methods, such as student evaluations, self-assessments, and teaching artifacts, as teaching is multidimensional and cannot be captured by one or two measures. 
There are several important limitations to note. First, out of 141 institutions contacted, 91 completed the survey for a response rate of $64.5 \%$. Despite having a response rate of less than $80 \%$, our respondents were proportionally representative of the institutional control $(p=0.80)$ and age of pharmacy schools $(p=0.58)$. Secondly, the study was limited to the responses obtained from the respondent for each institution and may not reflect all elements of that institution's PET/IC program accurately, particularly those aspects that the respondent was not aware of. To mitigate this potential limitation, when the survey was sent to respondents, they were asked to consult others as necessary and/or forward the survey to another individual more knowledgeable of the PET/IC program at their institution to complete, as appropriate. Third, the survey did not meaningfully distinguish between PET and IC. Future research should explore the differentiation between summative and formative approaches to improving teaching effectiveness in pharmacy education.

\section{CONCLUSION}

The use of PET/IC programs is an essential component to determining the effectiveness of teaching practices across the pharmacy academy. While most pharmacy schools have a PET/IC program, wide variability within these programs exist and gaps are evident in the use of PET/IC best practices. Many institutions have the opportunity to evaluate the effectiveness of their existing program to implement best practices that lead to meaningful impact on teaching and learning. Additional research is needed to further the development of PET/IC programs and instruments used to ensure that teaching practices are best preparing graduates within pharmacy education.

\section{REFERENCES}

1. MacDougall J, Drummond MJ. The development of medical teachers: an enquiry into the learning histories of 10 experienced medical teachers. Med Edu. 2005;39(12):1213-20.

2. Hartford W, Nimmon L, Stenfors T. Frontline learning of medical teaching: "you pick up as you go through work and practice". BMC Med Edu. 2017;17(1):1-10.

3. Accreditation Council for Pharmacy Education. Accreditation standards and key elements for the professional program in pharmacy leading to the doctor of pharmacy degree. Available from https://www.acpeaccredit.org/pdf/Standards2016FINAL.pdf. Accessed July 29, 2021.

4. Thampy H, Kersey N. Peer observation of clinical teaching: A guide. MedEdPublish. 2015;5:9.

5. Irby DM, Gillmore GM, Ramsey PG. Factors affecting ratings of clinical teachers by medical students and residents. J Med Educ. 1987;62(1):1-7.

6. Kidd RS, Latif DA. Student evaluations: Are they valid measures of course effectiveness? Am J Pharm Educ. 2004;68(3):61.

7. Hyland KM, Dhaliwal G, Goldberg AN, Chen L, Land K, Wamsley M. Peer review of teaching: Insights from a 10-year experience. Med Sci Educ. 2018;28:675-81.

8. Speer AJ, Elnicki DM. Assessing the quality of teaching. Am J Med. 1999;106:381-4.

9. Irby DM. Teaching and learning in ambulatory care settings: a thematic review of the literature. Acad Med. 1995;70:898-931.

10. Esarey J, Valdes N. Unbiased, reliable, and valid student evaluations can still be unfair. Assess Eval High Educ. 2020;45(8):1106-20.

11. Davis TS. Peer observation: A faculty initiative. Curr Pharm Teach Learn. 2011;3:106-15.

12. Trujillo JM, DiVall MV, Barr J, et al. Development of a peer teaching-assessment program and a peer observation and evaluation tool. Am J Pharm Educ. 2008;72(6):147.

13. DiVall M, Barr J, Gonyeau M, et al. Follow-up assessment of a faculty peer observation and evaluation program. Am J Pharm Educ. 2012;76(4):61.

14. Hansen LB, McCollum M, Paulsen SM. Evaluation of an evidence-based peer teaching assessment program. Am J Pharm Educ. 2007;71(3):45.

15. Schultz KK, Latif D. The planning and implementation of a faculty peer review teaching project. Am J Pharm Educ. 2006;70:32.

16. Wellein MG, Ragucci KR, Lapointe M. A peer review process for classroom teaching. Am J Pharm Educ. 2009;73:79.

17. Richard CL, Lillie E, Mathias K, McFarlane T. Impact and attitudes about peer review of teaching in a Canadian pharmacy school. Am J Pharm Educ. 2019;83(6):6828.

18. Moon JY, Schullo-Feulner AM, Kolar C, et al. Supporting formative peer review of clinical teaching through a focus on process. Curr Pharm Teach Learn. 2018;10(6):771-8. 
19. Olsen AA, Morbitzer KA, Zambrano S, Zeeman JM, Persky AM, Bush AA, McLaughlin JE. Development and implementation of a formative instructional coaching program using the Teaching Practices Inventory within a health professions program. BMC Med Ed. 2021. [under review].

20. Northern Michigan University. Peer evaluation of teaching. Available from https://nmu.edu/ctl/peerevaluationteaching\#: :text=Peer\%20Evaluation\%20of\%20Teaching\%20consists, the\%20quality\%20of\%20their\%20teac hing. Accessed August 27, 2021.

21. Lomas L, Nicholls G. Enhancing teaching quality through peer review of teaching. High Edu. 2005;11(2):137-49.

22. Davis TS. Peer observation: A faculty initiative. Curr Pharm Teach Learn. 2011;3(2):106-15.

23. Bell A, Thomson K. Supporting peer observation of teaching: Collegiality, conversations, and autonomy. Innovations in Education and Teaching International. 2016;55(3):276-84.

24. Chism N. Peer Review of Teaching: A Sourcebook. 2nd ed. Boston, MA: Anker Publishing Group; 2007.

25. Hammersley-Fletcher L, Orsmond P. Reflecting on reflective practices within peer observation. Studies in Higher Education. 2005;30(2):213-24.

26. Bell M, Cooper P. Peer observation of teaching in university departments: A framework for implementation. International Journal for Academic Development. 2013;18(1):60-73.

27. Hendry GD, Bell A, Thomson K. Learning by observing a peer's teaching situation. International Journal for Academic Development. 2013;19(4):318-29.

28. Bell A, Mladenovic R. Situated learning, reflective practice and conceptual expansion: Effective peer observation for tutor development. Teaching in Higher Education. 2015;20(1):24-36.

29. Barnard A, Croft W, Irons R, Cuffe N, Bandara W, Rowntree P. Peer partnership to enhance scholarship of teaching: A case study. Development. 2011;30(4):435-48.

30. Bell A, Thomson K. Supporting peer observation of teaching: Collegiality, conversations, and autonomy. Innovations in Education and Teaching International. 2018;55(3):276-84.

31. Peel D. Peer observation as a transformatory tool? Teaching in Higher Education. 2005;10(4):489-504.

32. Reynolds, Avin, Bao, et al. Teaching Evaluation Initiative (TEI). Center for Excellence in Teaching and Learning (CETL), Teaching Evaluation Initiative (TEI). https://www.uwec.edu/files/1478/TEI-Report-Sept10-2010.pdf. Published September 10, 2010. Accessed July 30, 2021.

33. Peyre SE, Frankl SE, Thorndike M, Breen EM. Observation of clinical teaching: Interest in a faculty development program for surgeons. J Surg Educ. 2011;68(5):372-76.

34. Trujillo JM, DiVall MV, Barr J, et al. Development of a peer teaching-assessment program and a peer observation and evaluation tool. Am J Pharm Educ. 2008;72(6):147.

35. Buchanan JA, Parry D. Engagement with peer observation of teaching by a dental school faculty in the United Kingdom. Eur J Dent Educ. 2018;23(1):42-53.

36. Torbeck L, Dunnington G. Development of a peer review of operative teaching process and assessment tool. Am J Surg. 2021;221(2):263-69.

37. Mazer LM, Hu YY, Arriaga AF, et al. Evaluating surgical coaching: a mixed methods approach reveals more than surveys alone. J Surg Educ. 2018;75(6):1520-25.

38. Ambler T, Chavan M, Clarke J, Matthews N. Climates of communication: Collegiality, affect, spaces and attitudes in peer review. Peer Review of Learning and Teaching in Higher Education. 2014:67-84. 
Table 1. Suggested Considerations for a Peer Evaluation of Teaching/Instructional Coaching Process.

- Establish a clear vision and purpose

- Build an Office of Teaching and Learning staffed by educational experts

- Identify the program leader and coordinator

- Identify participants and peer observers

- Establish a process that can be utilized for in-person or remote teaching

- Identify a validated peer evaluation instrument

- Provide training to peer evaluators to minimize bias

- Provide feedback and share results of the evaluation to the faculty member being reviewed

- Consider reviewing materials beyond classroom presentations, handouts, and assessments

- Consider having a pre-class meeting, classroom observation, and post-class meeting

- Include peer and student evaluations with self-reflection to minimize bias

- Consider engaging staff and senior faculty from different colleges and departments within the University who possess various expertise

- Emphasize principles of ownership, mutual respect, trust, confidentiality, inclusion, and engaging in scholarship of teaching and learning

- Affirm an accountability process to include rewards and recognition

- Recognize sociocultural differences and work to minimize any power dynamics and systematic barriers 
Table 2. Characteristics of PET/IC Programs at U.S. Schools/Colleges of Pharmacy

\begin{tabular}{|c|c|c|c|c|c|c|c|c|c|c|c|}
\hline \multirow[b]{2}{*}{ Survey Items } & & \multicolumn{2}{|c|}{$\begin{array}{l}\text { Private } \\
(\mathbf{n}=37)^{\mathrm{a}}\end{array}$} & \multicolumn{2}{|c|}{$\begin{array}{l}\text { Public } \\
(\mathbf{n}=32)^{\mathrm{a}}\end{array}$} & \multirow[b]{2}{*}{$p$ value } & \multicolumn{2}{|c|}{$\begin{array}{c}>10 \text { Years } \\
(n=61)^{a}\end{array}$} & \multicolumn{2}{|c|}{$\begin{array}{c}\text { 0-10 Years } \\
(n=8)^{a}\end{array}$} & \multirow[b]{2}{*}{$p$ value } \\
\hline & & Count & $\%$ & Count & $\%$ & & Count & $\%$ & Count & $\%$ & \\
\hline \multirow[t]{3}{*}{ Program Type } & Formative & 12 & $33.3 \%$ & 7 & $21.9 \%$ & \multirow[b]{2}{*}{.409} & 18 & $30.0 \%$ & 1 & $12.5 \%$ & \multirow[b]{2}{*}{.439} \\
\hline & Summative & 6 & $16.7 \%$ & 4 & $12.5 \%$ & & 8 & $13.3 \%$ & 2 & $25.0 \%$ & \\
\hline & Combination & 18 & $50.0 \%$ & 21 & $65.5 \%$ & & 34 & $56.7 \%$ & 5 & $62.5 \%$ & \\
\hline \multirow{2}{*}{$\begin{array}{l}\text { Affiliate Support } \\
\text { Center }\end{array}$} & None & 29 & $80.6 \%$ & 23 & $74.2 \%$ & .533 & 46 & $78.0 \%$ & 6 & $75.0 \%$ & 1.00 \\
\hline & Yes & 7 & $19.4 \%$ & 8 & $25.8 \%$ & & 13 & $22.0 \%$ & 2 & $25.0 \%$ & \\
\hline \multirow{2}{*}{$\begin{array}{l}\text { Mandatory } \\
\text { Participation }\end{array}$} & Other & 11 & $30.6 \%$ & 10 & $32.3 \%$ & .881 & 18 & $30.5 \%$ & 3 & $37.5 \%$ & .698 \\
\hline & All/Some & 25 & $69.4 \%$ & 21 & $67.7 \%$ & & 41 & $69.5 \%$ & 5 & $62.5 \%$ & \\
\hline \multirow{2}{*}{$\begin{array}{l}\text { Standardized } \\
\text { Instrument }\end{array}$} & None & 7 & $19.4 \%$ & 5 & $16.7 \%$ & .771 & 10 & $17.2 \%$ & 2 & $25.0 \%$ & .630 \\
\hline & $1+$ & 29 & $80.6 \%$ & 25 & $83.3 \%$ & & 48 & $82.8 \%$ & 6 & $75.0 \%$ & \\
\hline \multirow{2}{*}{$\begin{array}{l}\text { Adapted } \\
\text { Instrument }\end{array}$} & No & 15 & $51.7 \%$ & 16 & $64.0 \%$ & .363 & 30 & $62.5 \%$ & 1 & $16.7 \%$ & .073 \\
\hline & Yes & 14 & $48.3 \%$ & 9 & $36.0 \%$ & & 18 & $37.5 \%$ & 5 & $83.3 \%$ & \\
\hline \multirow{2}{*}{$\begin{array}{l}\text { Completion of In- } \\
\text { person Training } \\
\text { for Peer Observers }\end{array}$} & No & 31 & $88.6 \%$ & 25 & $80.6 \%$ & .496 & 51 & $87.9 \%$ & 5 & $62.5 \%$ & .095 \\
\hline & Yes & 4 & $11.4 \%$ & 6 & $19.4 \%$ & & 7 & $12.1 \%$ & 3 & $37.5 \%$ & \\
\hline \multirow{2}{*}{$\begin{array}{l}\text { Incentivized to } \\
\text { Observe }\end{array}$} & No & 29 & $82.9 \%$ & 30 & $100.0 \%$ & $.027 *$ & 52 & $91.2 \%$ & 7 & $87.5 \%$ & .561 \\
\hline & Yes & 6 & $17.1 \%$ & 0 & $0.0 \%$ & & 5 & $8.8 \%$ & 1 & $12.5 \%$ & \\
\hline \multirow[t]{2}{*}{ Evaluated PET/IC } & No & 28 & $77.8 \%$ & 23 & $74.2 \%$ & .732 & 46 & $78.0 \%$ & 5 & $62.5 \%$ & .385 \\
\hline & Yes/in process & 8 & $22.2 \%$ & 8 & $25.8 \%$ & & 13 & $22.0 \%$ & 3 & $37.5 \%$ & \\
\hline
\end{tabular}


${ }^{\text {a }}$ Some items were missing data, therefore counts for a survey item may sum to less than the full sample ${ }^{*} p<.05$ 